\title{
Metanálise dos níveis de ractopamina em dietas para suínos em terminação
}

\author{
Charles Kiefer $^{1}$, Josilene Figueiredo Sanches ${ }^{2}$
}

\author{
${ }^{1}$ Departamento de Zootecnia/FAMEZ/UFMS. \\ 2 Programa de Pós-Graduação em Ciência Animal/FAMEZ/UFMS.
}

RESUMO - Foi realizada uma metanálise para avaliar o desempenho e as características de carcaça de suínos em terminação alimentados com rações contendo ractopamina. Utilizaram-se resultados de 18 experimentos com 2.991 animais e 4 tratamentos, constituídos dos níveis de 0,5, 10 e 20 ppm de ractopamina. Foram analisados o desempenho e as características quantitativas da carcaça. A duração dos períodos experimentais foi de $28 \pm 0,32$ dias e os pesos inicial e final foram de $74,7 \pm 10,9 \mathrm{~kg}$ e $107,6 \pm 9,7 \mathrm{~kg}$, respectivamente. Não houve efeito dos níveis de ractopamina sobre o consumo de ração, o peso de carcaça quente, o comprimento de carcaça e a espessura de toucinho. Os níveis de ractopamina influenciaram o ganho de peso, a conversão alimentar, o rendimento de carcaça, a porcentagem de carne magra da carcaça e a área de olho-de-lombo. Houve efeito linear dos níveis de lisina sobre o ganho de peso, a conversão alimentar, o peso de carcaça quente, a espessura de toucinho e a porcentagem de carne magra nos suínos alimentados com rações contendo 20 ppm de ractopamina. A área de olho-de-lombo dos suínos alimentados com rações contendo 10 e 20 ppm de ractopamina variou de forma quadrática com os níveis de lisina. As demais variáveis não foram influenciadas pelos níveis de lisina. O nível de 15 ppm de ractopamina otimiza o desempenho dos suínos, enquanto o de 20 ppm de ractopamina melhora as características quantitativas de carcaça. O ganho de peso, a espessura de toucinho e o percentual de carne magra na carcaça de suínos alimentados com rações contendo ractopamina melhoram com o nível de 1,0\% de lisina digestível verdadeira.

Palavras-chave: aditivos, características de carcaça, carne magra, lisina, nutrição

\section{Meta-analysis of the ractopamine levels in diets for finishing pigs}

ABSTRACT - A meta-analytical study was conducted to evaluate the performance and characteristics of the carcass of finishing pigs fed with diets containing ractopamine. Eighteen experiments containing four treatments and 2.991 animals were used. The treatments were composed of $0,5,10$ and $20 \mathrm{ppm}$ of ractopamine levels. The variables of performance and the quantitative characteristics of the carcass were analyzed. The average duration of the experimental periods was $28 \pm 0.32$ days. The average initial and final weights were $74.7 \pm 10.9 \mathrm{~kg}$ and $107.6 \pm 9.7 \mathrm{~kg}$, respectively. No effect of ractopamine levels on the feed intake, hot carcass weight, carcass length and backfat depth was observed. The ractopamine levels influenced the weight gain, the feed:gain ratio, the dressing percent, the lean meat percentage of the carcass and the loin eye area. A linear effect was verified from the lysine levels of the weight gain, gain:feed ratio, hot carcass weight, backfat depth and lean meat percentage of pigs feed diet with $20 \mathrm{ppm}$ of ractopamine. Effect from the loin eye area in function from the lysine levels in the diets containing 10 and $20 \mathrm{ppm}$ of ractopamine was observed. Most of the variables was not influenced by the lysine levels. Levels of $15 \mathrm{ppm}$ of ractopamine optimize the swine performance, while levels of $20 \mathrm{ppm}$ of ractopamine optimize the quantitative carcass characteristics. Weight gain, backfat depth and lean meat carcass percent of swine fed diets containing ractopamine are optimized with $1.0 \%$ of true digestible lysine.

Key Words: additives, carcass characteristics, lean meat, lysine, nutrition

\section{Introdução}

O mercado consumidor está cada vez mais exigente quanto à qualidade dos produtos cárneos e, para atender essas exigências, diversas pesquisas têm sido realizadas para encontrar alternativas que permitam reduzir a deposição de gordura e aumentar a produção e a porcentagem de carne magra na carcaça dos suínos, potencializando também seu desempenho.

Entre as alternativas, está a ractopamina, um aditivo beta-adrenérgico utilizado como repartidor de energia em dietas para suínos na fase de terminação com o propósito de melhorar o desempenho e as características de carcaça. A ractopamina aumenta a deposição de proteína (Apple 
et al., 2004) e reduz a deposição de gordura na carcaça (Perez et al., 2006), mas não altera a qualidade da carne suína em termos de cor, marmoreio, firmeza e pH (Herr et al., 2000).

O aumento da deposição de proteína corporal proporcionado pela utilização da ractopamina é maior na carcaça que nas vísceras, o que melhora o rendimento de carcaça dos suínos (Schinckel et al., 2002). Além disso, dietas contendo $10 \mathrm{ppm}$ de ractopamina têm proporcionado redução do consumo de alimento (Brumm et al., 2004), aumento do ganho de peso (Armstrong et al., 2004) e melhora na eficiência de utilização dos alimentos em suínos (Mimbs et al., 2005). Em situações práticas, níveis de 5 a 10 ppm resultam em ganho de peso satisfatório, porém níveis maiores, em torno de 20 ppm, proporcionam máxima eficiência alimentar e melhores características quantitativas das carcaças dos suínos (See et al., 2004).

Diversas pesquisas têm sido desenvolvidas com o objetivo de avaliar o uso da ractopamina na nutrição de suínos, gerando grande quantidade de informações científicas. A partir dessas informações, é possível realizar uma metanálise, um procedimento que consiste em combinar resultados de vários estudos para fazer uma síntese reproduzível e quantificável dos dados (Lovatto et al., 2007). Para isso, as informações são extraídas de trabalhos preexistentes, pela união dos resultados e aplicação de técnicas estatísticas, sintetizando as conclusões obtidas ou até mesmo formando nova conclusão (Luiz, 2002).

Considerando o efeito da utilização de ractopamina em dietas para suínos sobre o aumento do percentual de carne magra na carcaça, proporcionado pelo aumento da síntese protéica, e a existência de interação entre deposição de carne magra e a exigência aminoacídica (Apple et al., 2004), propôs-se realizar esta pesquisa com o objetivo de comparar dietas contendo diferentes níveis de ractopamina e lisina e avaliar seus efeitos sobre o desempenho e as características quantitativas das carcaças de suínos em fase de terminação por meio de um estudo metanalítico.

\section{Material e Métodos}

O trabalho foi realizado no Departamento de Zootecnia da Faculdade de Medicina Veterinária e Zootecnia da Universidade Federal de Mato Grosso do Sul, em Campo Grande,Mato Grosso doSul.Para realizar o estudo metanalítico, foram selecionados e coletados dados de artigos científicos nacionais e internacionais publicados no período de 1990 a 2007 sobre a associação entre desempenho e características de carcaça de suínos e a suplementação de ractopamina nas dietas. Foram identificadas 52 publicações e excluídas 34 após leitura dos artigos.

Na seleção dos artigos, foi feita restrição pela fase de criação e pela duração da administração da ractopamina nas dietas, elegendo-se artigos nos quais foram utilizados suínos em fase de terminação com suplementação de ractopamina durante 28 dias. A base de dados foi composta de 18 publicações (Tabela 1), quatro níveis de ractopamina $(0,5,10$ e 20 ppm) e 2.991 suínos avaliados. O peso inicial dos animais foi de $74,67 \pm 10,92 \mathrm{~kg}$ e o peso final, de 107,56 $\pm 9,75 \mathrm{~kg}$. O tempo médio de duração dos períodos experimentais foi de $28 \pm 0,32$ dias.

Os níveis de lisina digestíveis verdadeiros utilizados nas dietas experimentais das pesquisas foram estimados

Tabela 1 - Características das pesquisas utilizadas na metanálise sobre o uso de ractopamina em rações para suínos em fase de terminação

\begin{tabular}{|c|c|c|c|c|c|c|}
\hline \multirow{2}{*}{$\frac{\text { Autor }}{\text { Watkins et al. (1990) }}$} & \multirow{2}{*}{$\frac{\text { Animais, } \mathrm{n}^{\circ}}{888}$} & \multirow{2}{*}{$\frac{\text { Lisina, \%* }}{0,667}$} & \multicolumn{4}{|c|}{ Nível de ractopamina, ppm } \\
\hline & & & 0 & 5 & 10 & 20 \\
\hline & 368 & 0,667 & 0 & 5 & 10 & 20 \\
\hline Stites et al. (1991) & 60 & 0,656 & 0 & 5 & 10 & 20 \\
\hline Bark et al. (1992) & 32 & 0,795 & 0 & - & - & 20 \\
\hline Dushea et al. (1993) & 20 & 0,945 & 0 & - & - & 20 \\
\hline Smith et al. (1995) & 80 & 0,644 & 0 & 5 & 10 & 20 \\
\hline Crome et al. (1996) & 72 & 0,714 & 0 & - & 10 & 20 \\
\hline Herr et al. (2000) & 300 & 0,873 & 0 & 5 & 10 & 20 \\
\hline Trapp et al. (2002) & 108 & 0,947 & 0 & 5 & - & - \\
\hline Marchant-Forde et al. (2003) & 72 & 0,899 & 0 & - & 10 & - \\
\hline Stoller et al. (2003) & 75 & 0,869 & 0 & - & 10 & - \\
\hline Armstrong et al. (2004) & 192 & 0,960 & 0 & 5 & 10 & 20 \\
\hline Brumm et al. (2004) & 132 & 0,804 & 0 & - & 10 & - \\
\hline See et al. (2004) & 100 & 0,938 & 0 & - & 10 & - \\
\hline Carr et al. (2005a) & 32 & 0,805 & 0 & - & 10 & - \\
\hline Carr et al. (2005b) & 180 & 0,997 & 0 & - & 10 & 20 \\
\hline Mimbs et al. (2005) & 144 & 0,958 & 0 & - & 10 & - \\
\hline Weber et al. (2006) & 76 & 0,909 & 0 & - & 10 & - \\
\hline Marinho et al. (2007) & 60 & 0,885 & 0 & 5 & - & - \\
\hline
\end{tabular}

* Nível de lisina digestível verdadeiro estimado segundo Rostagno et al. (2005). 
com base na composição centesimal das rações experimentais apresentadas e de acordo com os coeficientes de digestibilidade verdadeira da lisina dos alimentos utilizados, conforme informações descritas por Rostagno et al. (2005). Os níveis estimados de lisina digestível verdadeira dos estudos variaram de 0,64 a $1,00 \%$.

Foram analisadas as características de desempenho (ganho de peso, consumo de ração e a conversão alimentar) e as características quantitativas da carcaça (peso de carcaça quente, o rendimento de carcaça, a espessura de toucinho, o percentual de carne magra, o comprimento de carcaça e a área de olho-de-lombo).

A metanálise das variáveis envolveu as seguintes etapas: análise exploratória do conjunto de dados, verificação das pressuposições estatísticas exigidas e teste de homogeneidade. A análise exploratória do conjunto de dados foi realizada por meio do dispositivo gráfico "boxplot" e também pela verificação gráfica de "outliers" visando detectar observações discrepantes. A pressuposição de normalidade dos dados foi testada pelo teste de Shapiro-Wilk, cuja hipótese de nulidade indicou distribuição normal dos dados. O teste Hartley foi utilizado para verificar a homogeneidade das variâncias.

Atendidas as pressuposições, foram realizadas as análises de variância para análise da existência de interação entre os níveis de ractopamina e os de lisina e as análises de regressão pelo método de mínimos quadrados ponderados para número de animais de cada pesquisa, considerando o modelo:

$$
\hat{y}_{i j k}=\mu+\text { Trat }+ \text { Exper }+R_{i}+L_{j}+R_{i j}+e_{i j k}
$$

em que: $\hat{\mathrm{y}}_{\mathrm{ijk}}=$ estimativa da média das variáveis estudadas ponderada para o número de animais de cada estudo; $\mathrm{R}_{\mathrm{i}}=$ efeito do $i$-ésimo nível de ractopamina; $\mathrm{L}_{\mathrm{j}}=$ efeito do j-ésimo nível de lisina; $\mathrm{RL}_{\mathrm{ij}}=$ efeito da interação entre os fatores anteriores; $\mathrm{e}_{\mathrm{ijkl}}=$ erro aleatório associado à observação $\mathrm{y}_{\mathrm{ijk}}$.

Posteriormente, realizou-se a análise de regressão dos dados para cada variável, dentro de cada nível de ractopamina avaliado, em cada nível de lisina digestível verdadeiro estimado das dietas experimentais, adotando-se os modelos de regressão linear ou quadrático, conforme o melhor ajuste do modelo obtido para cada variável. As análises estatísticas foram realizadas pelo programa estatístico Statistical Analysis System (SAS, 2002) utilizando-se o nível de 5\% de significância.

\section{Resultados e Discussão}

Os valores da estatística do teste de Shapiro-Wilk para normalidade não foram significativos $(\mathrm{P}>0,05)$ e evidenciam distribuição normal dos dados. O prosseguimento da análise se deu com o teste de homogeneidade das variâncias, no qual a hipótese de homogeneidade entre as variáveis foi aceita.

Não foram observados efeito de interação $(P>0,05)$ dos níveis de ractopamina e de lisina sobre as características de desempenho (Tabela 2). Também não houve efeito ( $\mathrm{P}>0,05)$ dos níveis de ractopamina sobre os pesos médio inicial e final dos animais. $\mathrm{O}$ ganho de peso e a conversão alimentar foram influenciados $(\mathrm{P}<0,01)$ pelos níveis de ractopamina e variaram de forma quadrática com o aumento do nível de ractopamina nas dietas (Figura 1), sendo que o ganho de peso aumentou até o nível de 14,5 ppm e a conversão alimentar melhorou até o nível de 15,3 ppm. Os níveis de ractopamina não influenciaram $(\mathrm{P}>0,05)$ o consumo de ração dos animais.

A constatação de que dietas contendo ractopamina influenciam o ganho de peso e a eficiência de utilização dos

Tabela 2 - Desempenho e características de carcaça de suínos em fase de terminação alimentados com rações contendo ractopamina

\begin{tabular}{|c|c|c|c|c|c|c|}
\hline \multirow[t]{2}{*}{ Variável } & \multicolumn{4}{|c|}{ Nível de ractopamina, ppm } & \multirow[t]{2}{*}{$\mathrm{CV}, \%$} & \multirow[t]{2}{*}{$\mathrm{P}<$} \\
\hline & 0 & 5 & 10 & 20 & & \\
\hline Peso médio inicial, kg & 75,57 & 72,67 & 76,96 & 70,87 & 14,78 & 0,57 \\
\hline $\begin{array}{l}\text { Peso médio final, kg } \\
\text { Desempenho }\end{array}$ & 106,54 & 109,03 & 108,77 & 106,68 & 9,35 & 0,91 \\
\hline Ganho de peso, g/dia ${ }^{* *}$ & 905 & 945 & 988 & 990 & 10,92 & 0,01 \\
\hline Consumo de ração, $\mathrm{kg} / \mathrm{dia}$ & 2,91 & 2,82 & 2,76 & 2,77 & 10,15 & 0,22 \\
\hline $\begin{array}{l}\text { Conversão alimentar, } \mathrm{kg} / \mathrm{kg} \\
\text { Características de carcaça }\end{array}$ & 3,23 & 3,00 & 2,84 & 2,86 & 10,74 & 0,01 \\
\hline Peso de carcaça quente, $\mathrm{kg}$ & 79,99 & 80,74 & 82,82 & 82,93 & 6,61 & 0,14 \\
\hline Comprimento de carcaça, $\mathrm{cm}$ & 80,48 & 78,82 & 79,68 & 78,86 & 3,91 & 0,57 \\
\hline Rendimento de carcaça, \% ${ }^{*}$ & 74,38 & 74,51 & 75,24 & 76,33 & 2,72 & 0,01 \\
\hline Espessura de toucinho, mm & 2,17 & 2,09 & 2,06 & 2,04 & 21,94 & 0,43 \\
\hline Carne magra, $\%^{*}$ & 54,04 & 54,44 & 55,39 & 55,78 & 4,49 & 0,01 \\
\hline Área de olho-de-lombo, $\mathrm{cm}^{2} * *$ & 38,18 & 39,60 & 42,09 & 42,59 & 9,90 & 0,01 \\
\hline
\end{tabular}

*Efeito linear; ${ }^{* *}$ Efeito quadrático. 


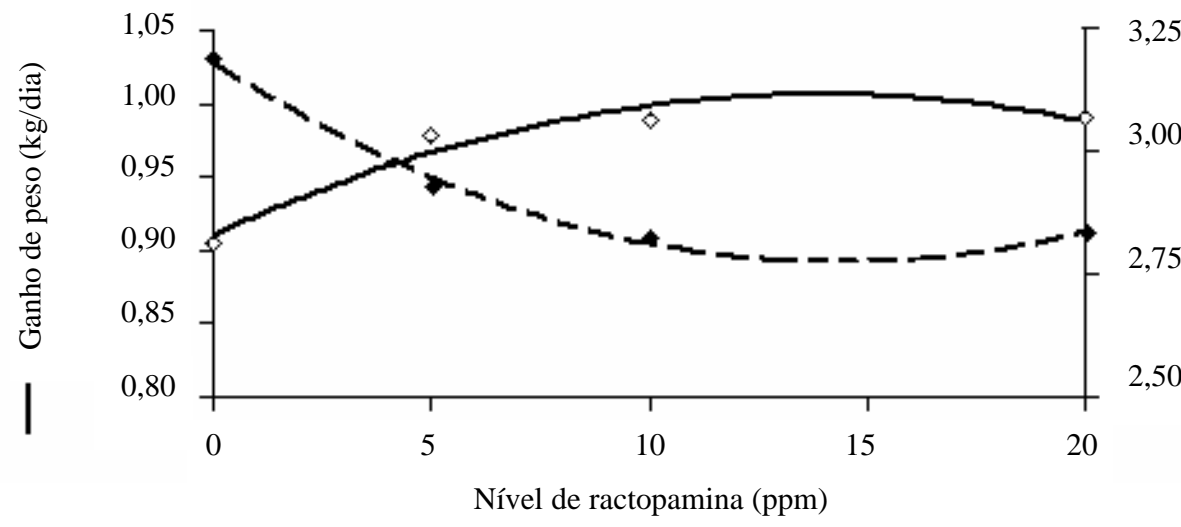

Figura 1 - Ganho de peso e conversão alimentar de suínos em fase de terminação alimentados com rações contendo ractopamina. Equação de regressão: GP: $\hat{Y}=0,8569+0,0137 x-0,000474 x^{2}, r^{2}=0,93 ; C A: \hat{Y}=3,4361-0,06014 x+0,00196 x^{2}, r^{2}=0,99$.

alimentos foi verificada em estudos anteriores descritos por See et al. (2004), Carr et al. (2005a) e Marinho et al. (2007), que verificaram aumento do ganho e melhora da conversão alimentar de suínos alimentados com rações contendo 5,10 ou 20 ppm de ractopamina em relação àqueles alimentados com ração sem ractopamina. Esses mesmos pesquisadores não constataram efeito da ractopamina sobre o consumo de ração.

Crome et al. (1996), no entanto, verificaram redução linear do consumo e aumento linear da eficiência alimentar com o aumento dos níveis de ractopamina nas dietas. Mimbs et al. (2005) também observaram que o aumento do nível de ractopamina reduziu o consumo de alimento, sem alterar o ganho de peso, melhorando a eficiência alimentar dos suínos.

O efeito da ractopamina sobre o ganho de peso pode ser explicado pelas alterações metabólicas provocadas por este aditivo, principalmente no aumento da síntese protéica (Schinkel et al., 2003). O aumento da deposição de proteína na carcaça, por agregar $35 \%$ de água, é um dos principais fatores relacionados ao aumento do ganho de peso e à melhora da eficiência alimentar (Marinho et al., 2007).

Foi observada interação $(\mathrm{P}<0,05)$ dos níveis de ractopamina e de lisina para a espessura de toucinho. Para as demais características quantitativas de carcaça avaliadas, não houve interação $(\mathrm{P}>0,05)$.

Não foi constatado efeito $(\mathrm{P}>0,05)$ dos níveis de ractopamina sobre o peso de carcaça quente e o comprimento de carcaça. Armstrong et al. (2004), no entanto, verificaram melhora no peso de carcaça quente com a suplementação de 5,10 ou 20 ppm de ractopamina em relação à dieta controle. Também See et al. (2004) e Carr et al. (2005a) não constataram efeito dos níveis de ractopamina sobre o comprimento de carcaça dos suínos. Entretanto, Carr et al. (2005a) verificaram que o peso de carcaça quente aumentou de acordo com a concentração de ractopamina na dieta. Aumento do peso de carcaça quente também foi verificado por Crome et al. (1996), Herr et al. (2000a) e See et al. (2004).

A suplementação de ractopamina influenciou $(\mathrm{P}<0,01)$ o rendimento de carcaça, pois o aumento do seu nível na dieta aumentou linearmente o rendimento $(\hat{Y}=74,268095+$ 0,099962x). Aumento do rendimento de carcaça proporcionado pelos níveis de ractopamina da dieta também foi obtido por Armstrong et al. (2004), See et al. (2004) e Carr et al. (2005a).

Os níveis de ractopamina também influenciaram $(\mathrm{P}<0,01)$ a porcentagem de carne magra da carcaça e a área de olho-de-lombo, que aumentaram linearmente de acordo com o nível de ractopamina na dieta (Figura 2).

Aumentos do percentual de carne magra na carcaça e da área de olho-de-lombo também foram obtidos por See et al. (2004) e Carr et al. (2005a), que adicionaram 10 e 20 ppm de ractopamina em dietas para suínos em terminação. Também Marinho et al. (2007) observaram aumentos da profundidade de lombo e da porcentagem de carne magra utilizando apenas $5 \mathrm{ppm}$ de ractopamina.

Por outro lado, Stoller et al. (2003) observaram que a suplementação de 10 ppm de ractopamina à dieta aumentou a área de olho-de-lombo, mas não melhorou a porcentagem de carne magra na carcaça. De acordo com os resultados obtidos neste estudo, é possível que as características de desempenho (ganho de peso e conversão alimentar) melhorem com níveis mais baixos de ractopamina ( 15 ppm) em relação aos níveis necessários para melhorar as características de carcaça, como a área de olho-de-lombo e o percentual de carne magra (20 ppm). 


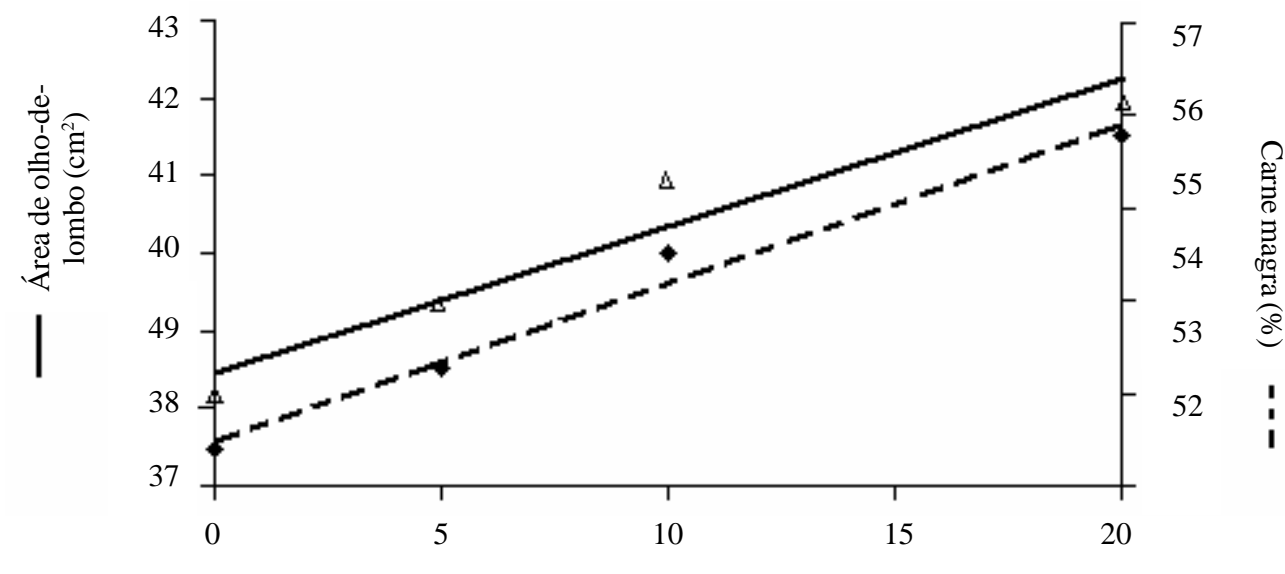

Nível de ractopamina (ppm)

Figura 2 - Área de olho-de-lombo (AOL) e percentual de carne magra (CM) de suínos em fase de terminação alimentados com rações contendo ractopamina.

Equações de regressão: AOL: $\hat{\mathrm{Y}}=36,32414+0,24146 \mathrm{x}, \mathrm{r}^{2}=0,92 ; \mathrm{CM}: \hat{\mathrm{Y}}=52,6288+0,1611 \mathrm{x}, \mathrm{r}^{2}=0,98$.

Esses resultados confirmam as considerações de Brumm et al. (2004) de que baixos níveis de inclusão de ractopamina (5 ppm) em dietas de suínos promovem boa resposta para o ganho de peso e a eficiência alimentar e, em menor grau, para os parâmetros de carcaça. Conforme descrito por Crome et al. (1996), embora possam melhorar o ganho e a eficiência alimentar, doses mais elevadas de ractopamina (20 ppm) promovem impacto mais pronunciado sobre as características quantitativas da carcaça.

Tem-se constatado que o ganho de peso melhora com níveis mais baixos e diminui com níveis maiores que 20 ppm, em virtude do efeito redutor da ractopamina sobre o consumo de alimento (Crome et al., 1996). Analisando-se o desempenho e as características de carcaça em função dos níveis de lisina digestíveis verdadeiros (Tabela 3), verificou-se que o ganho de peso dos suínos aumentou de forma linear $(\mathrm{P}<0,05)$ com o aumento dos níveis de lisina na dieta em todos os níveis de ractopamina, inclusive para a dieta sem ractopamina (Figura 3).

Não houve efeito $(\mathrm{P}>0,05)$ dos níveis de lisina sobre o consumo de ração. A conversão alimentar, quando fornecidas as rações contendo 0,5 e $10 \mathrm{ppm}$ de ractopamina, não foi influenciada $(\mathrm{P}>0,05)$ pelo aumento da concentração de lisina na dieta, mas reduziu de forma linear $(\mathrm{P}<0,05)$, de acordo com os níveis de lisina na dieta ( $\hat{Y}=4,197274$ $\left.1,66347 \mathrm{x}, \mathrm{r}^{2}=0,54\right)$, nos animais alimentados com rações contendo $20 \mathrm{ppm}$ de ractopamina.

O aumento do nível de lisina na dieta melhorou de forma linear $(\mathrm{P}<0,05)$ o peso de carcaça quente dos animais alimentados com rações contendo $5 \mathrm{ppm}(\hat{\mathrm{Y}}=60,373034+$ $\left.25,050259 \mathrm{x}, \mathrm{r}^{2}=0,62\right), 10 \mathrm{ppm}(\hat{\mathrm{Y}}=62,123588+23,327498 \mathrm{x}$, $\left.\mathrm{r}^{2}=0,53\right)$ e $20 \mathrm{ppm}\left(\hat{\mathrm{Y}}=59,252012+28,247828 \mathrm{x}, \mathrm{r}^{2}=0,61\right)$
Tabela 3 - Desempenho e características de carcaça de suínos em fase de terminação alimentados com rações contendo ractopamina

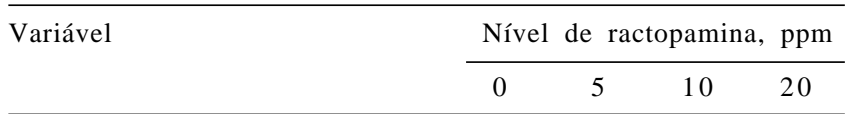

\section{Desempenho}

$\begin{array}{llllll}\text { Ganho de peso, } \mathrm{kg} / \mathrm{dia}^{* *} & \mathrm{~L} & \mathrm{~L} & \mathrm{~L} & \mathrm{~L}\end{array}$

$\begin{array}{lllll}\text { Consumo de ração, } \mathrm{kg} & \mathrm{NS} & \mathrm{NS} & \mathrm{NS} & \mathrm{NS}\end{array}$

Conversão alimentar, $\mathrm{kg} / \mathrm{kg}{ }^{* *} \quad$ NS NS NS L

Características de carcaça

Peso de carcaça quente, $\mathrm{kg}$ Comprimento de carcaça, cm

Rendimento de carcaça, \% *

Espessura de toucinho, mm

Carne magra, \%*

Área de olho-de-lombo, $\mathrm{cm}^{2}{ }^{* *}$

NS L L L

NS Efeito ñ̃o-significativo; L Efeito linear: $Q$ Efeito quadrico.

de ractopamina. Por outro lado, os níveis de lisina não influenciaram $(\mathrm{P}>0,05)$ o peso de carcaça quente dos animais alimentados com a ração controle (sem ractopamina).

Os níveis de lisina não influenciaram $(\mathrm{P}>0,05)$ o comprimento e o rendimento de carcaça dos suínos. Em todos níveis de ractopamina estudados, assim como na dieta controle, verificou-se aumento linear $(\mathrm{P}<0,05)$ da porcentagem de carne magra na carcaça dos suínos (Figura 4) com o aumento dos níveis de lisina da dieta.

Os níveis de ractopamina e lisina interagem $(\mathrm{P}<0,05)$, uma vez que o aumento de suas concentrações nas dietas promoveu redução da espessura de toucinho (Figura 5). Armstrong et al. (2004) também verificaram que a inclusão de ractopamina na dieta de suínos promove redução da espessura de toucinho. Da mesma forma, Crome et al. (1996), 


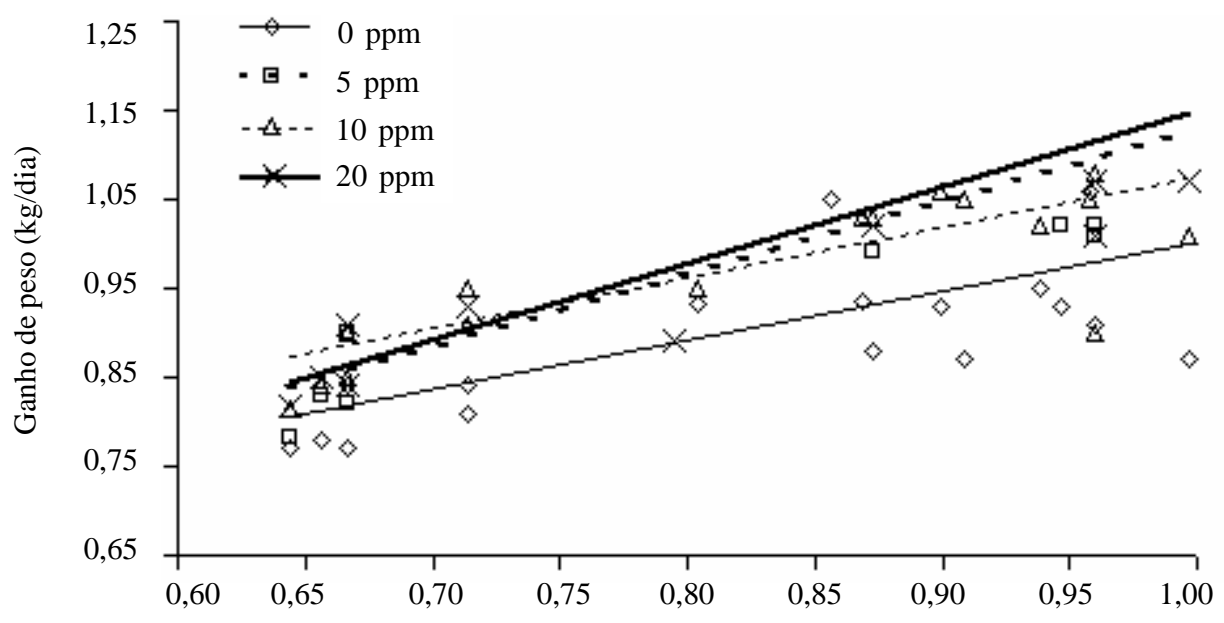

Lisina digestível verdadeira (\%)

Figura 3 - Ganho de peso de suínos em terminação alimentados com rações com ractopamina e lisina.

Equações de regressão: 0 ppm $\hat{Y}=0,617068+0,265436 x, r^{2}=0,49 ; 5$ ppm $\hat{Y}=0,416127+0,633335 x, r^{2}=0,88 ; 10$ ppm $\hat{Y}=0,513878$ $+0,520150 \mathrm{x}, \mathrm{r}^{2}=0,60 ; 20 \mathrm{ppm} \hat{\mathrm{Y}}=0,432927+0,642991 \mathrm{x}, \mathrm{r}^{2}=0,89$.

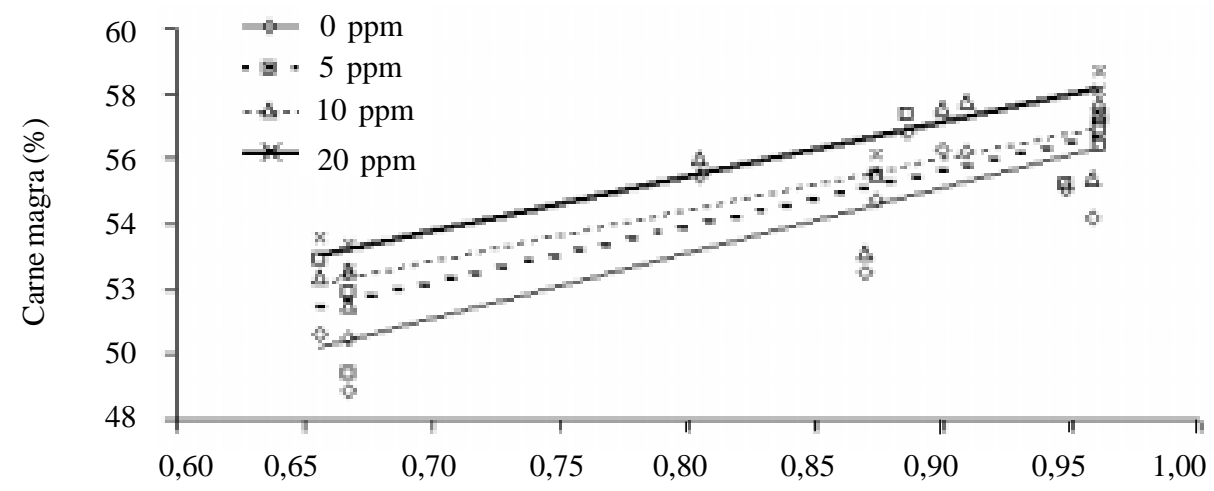

Lisina digestível verdadeira (\%)

Figura 4 - Percentual de carne magra de suínos em fase de terminação alimentados com rações contendo ractopamina e lisina. Equações de regressão: 0 ppm $\hat{\mathrm{Y}}=33,875036+24,271333 \mathrm{x}, \mathrm{r}^{2}=0,96 ; 5 \mathrm{ppm} \hat{\mathrm{Y}}=39,65378+17,785348 \mathrm{x}, \mathrm{r}^{2}=0,83 ; 10 \mathrm{ppm} \hat{\mathrm{Y}}=40,36484$ $+17,748476 \mathrm{x}, \mathrm{r}^{2}=0,97 ; 20 \mathrm{ppm} \hat{\mathrm{Y}}=41,86291+17,17048 \mathrm{x}, \mathrm{r}^{2}=0,96$.

Herr et al. (2000a) e See et al. (2004) verificaram redução da espessura de toucinho com o aumento do nível de ractopamina na dieta. Por outro lado, Carr et al. (2005a) não verificaram efeito do aumento da concentração de ractopamina na dieta sobre a espessura de toucinho.

A área de olho-de-lombo nos animais alimentados com as rações contendo 0 e 5 ppm não foi influenciada $(\mathrm{P}<0,05)$ pelos níveis de lisina na dieta. Contudo, as áreas de olho-de-lombo dos suínos alimentados com as rações contendo 10 e 20 ppm de ractopamina variaram de forma quadrática $(\mathrm{P}<0,05)$ e aumentaram até o nível estimado de $0,81 \%$ de lisina digestível verdadeira. Assim, é possível que as respostas de ganho de peso, percentual de carne magra e espessura de toucinho nos suínos alimentados com rações contendo ractopamina estejam relacionadas à concentração de lisina na dieta e que melhorem de forma linear até o nível de lisina digestível verdadeiro máximo avaliado neste estudo (1,00\%).

Os resultados obtidos neste estudo comprovam que, para melhorar o desempenho e as características de carcaça, 


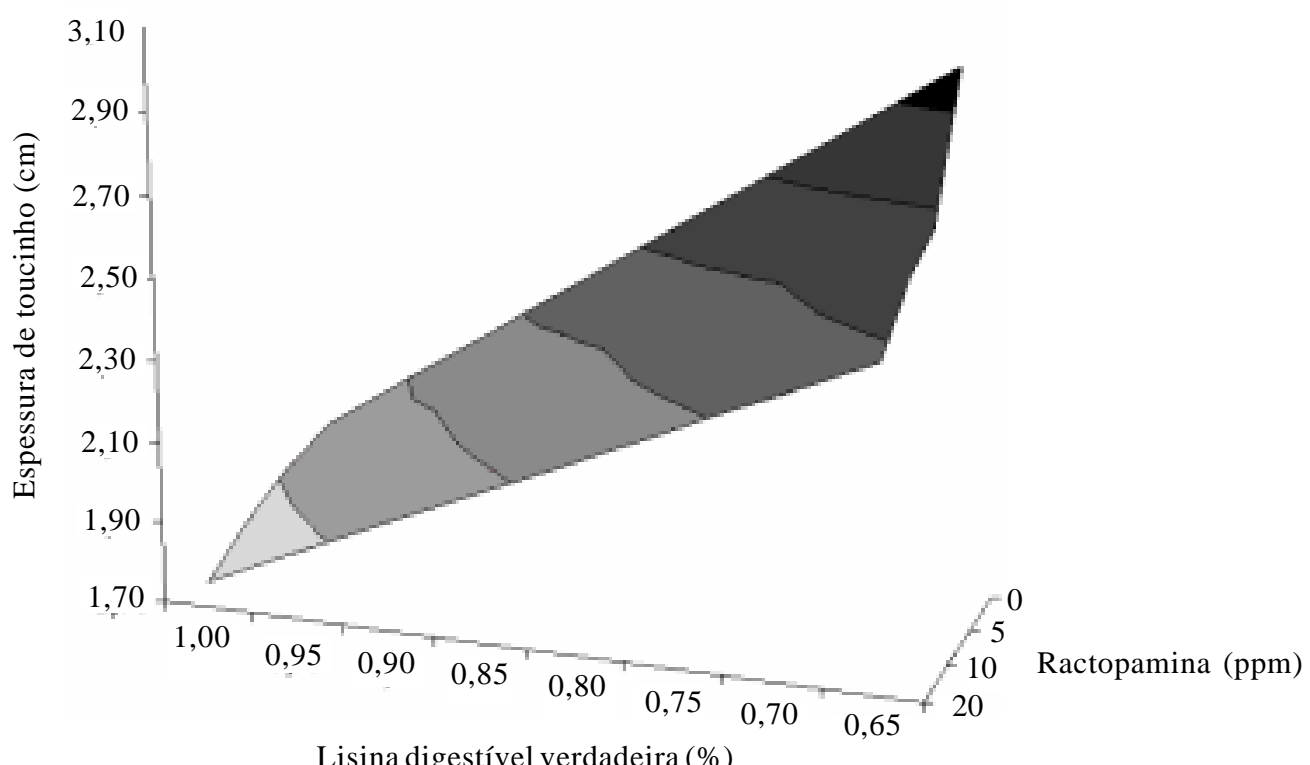

Figura 5 - Espessura de toucinho de suínos em fase de terminação alimentados com rações contendo ractopamina e lisina.

Equações de regressão: 0 ppm $\hat{\mathrm{Y}}=4,728600-2,971273 \mathrm{x}, \mathrm{r}^{2}=0,78 ; 5 \mathrm{ppm} \hat{\mathrm{Y}}=4,049877-2,130308 \mathrm{x}, \mathrm{r}^{2}=0,50 ; 10 \mathrm{ppm} \hat{\mathrm{Y}}=3,975437$ $-2,126829 x, r^{2}=0,60 ; 20$ ppm $\hat{Y}=3,776634-2,013340 x, r^{2}=0,57$.

suínos alimentados com rações contendo ractopamina exigem no mínimo $1,00 \%$ de lisina na dieta (Webster et al., 2002).

Conforme descrito por Apple et al. (2004), o desempenho e as características de carcaça de suínos alimentados com rações contendo ractopamina não são influenciados pela densidade energética da dieta, contudo a resposta de desempenho e das características de carcaça depende da concentração de lisina na dieta.

Da mesma forma, Marinho et al. (2007) constataram que a utilização de dietas contendo ractopamina e formuladas com excesso de alguns aminoácidos, segundo o padrão de proteína ideal, melhorou o desempenho de suínos em terminação em relação a dietas formuladas com os níveis de aminoácidos recomendados na literatura.

$\mathrm{O}$ aumento da exigência de aminoácidos dos suínos alimentados com rações contendo ractopamina pode estar relacionado à deposição diária de proteína na carcaça (Schinckel et al., 2003), que aumenta da eficiência de retenção do nitrogênio ingerido (DeCamp et al., 2001) e a concentração de lisina na proteína depositada e, desse modo, muitas vezes, a relação de aminoácidos proposta na proteína ideal pelas tabelas de exigências nutricionais pode não ser suficiente para atender à deposição protéica.

\section{Conclusões}

O nível de 15 ppm de ractopamina melhora o desempenho dos suínos e o de 20 ppm melhora as características quantitativas das carcaças. O ganho diário de peso, a espessura de toucinho e o percentual de carne magra na carcaça de suínos alimentados com rações contendo ractopamina melhoram com níveis de 1,0\% de lisina digestível verdadeira na dieta. Os níveis de ractopamina e de lisina na dieta interagem reduzindo a espessura de toucinho dos suínos. O estudo evidencia a importância da reavaliação das exigências aminoacídicas dos suínos em fase de terminação alimentados com rações contendo ractopamina.

\section{Literatura Citada}

APPLE, J.K.; MAXWELL, C.V.; BROWN, D.C. et al. Effects of dietary lysine and energy density on performance and carcass characteristics of finishing pigs fed ractopamine. Journal of Animal Science, v.82, p.3277-3287, 2004.

ARMSTRONG, T.A.; IVERS, D.J.; WAGNER, J.R. et al. The effect of dietary ractopamine concentration and duration of feeding on growth performance, carcass characteristics, and meat quality of finishing pigs. Journal of Animal Science, v.82, p.3245-3253, 2004.

BARK, L.J.; STAHLY, T.S.; CROMWELL, G.L. et al. Influence of genetic capacity for lean tissue growth on rate and efficiency 
of tissue accretion in pigs fed ractopamine. Journal of Animal Science, v.70, p.3391-3400, 1992.

BRUMM, M.C.; MILLER, P.S.; THALER, R.C. Response of barrows to space allocation and ractopamine. Journal of Animal Science, v.82, p.3373-3379, 2004.

CARR, S.N.; IVRES, D.J.; ANDERSON, D.B. et al. The effects of ractopamine hydrochloride on lean carcass yields and pork quality characteristics. Journal of Animal Science, v.83, p.2886-2893, 2005a.

CARR, S.N.; RINCKER, P.J.; KILLEFER, J. et al. Effects of different cereal grains and ractopamine hydrochloride on performance, carcass characteristics, and fat quality in latefinishing pigs. Journal of Animal Science, v.83, p.223-230, 2005b.

CROME, P.K.; McKEITH, F.K.; CARR, T.R. et al. Effect of ractopamine on growth performance, carcass composition, and cutting yields of pigs slaughtered at 107 and 125 kilograms. Journal of Animal Science, v.74, p.709-716, 1996.

DUNSHEA, F.R.; KING, R.H.; CAMPBELL, R.G. et al Interrelationships between sex and ractopamine on protein and lipid deposition in rapidly growing pigs. Journal of Animal Science, v.71, p.2919-2930, 1993.

HERR, C.T.; HANKINS, S.L.; SCHINCKEL, A.P. et al. Evaluation of three genetic populations of pigs for response to increasing levels of Paylean. West Lafayette: Purdue University, 2000a. 31p.

HERR, C.T.; YAKE, W.; ROBSON, C. et al. Effect of nutritional level while feeding paylean to late-finishing swine. Purdue University Swine day, v.21, p.89-95, 2000b.

LOVATTO, P.A.; LEHNEN, C.R.; ANDRETTA, I. et al. Meta análise em pesquisas científicas - enfoque em metodologias. Revista Brasileira de Zootecnia, v.36, p.285-294, 2007.

LUIZ, A.J.B. Meta-análise: definição, aplicações, e sinergia com dados espaciais. Cadernos de Ciência e Tecnologia, v.19, n.3, p.407-428, 2002

MARCHANT-FORDE, J.N.; LAY JR., D.C.; PAJOR, E.A. et al. The effects of ractopamine on the behavior and physiology of finishing pigs. Journal of Animal Science, v.81, p.416-422, 2003.

MARINHO, P.C.; FONTES, D.O.; SILVA, F.C.O. et al. Efeito da ractopamina e de métodos de formulação de dietas sobre o desempenho e as características de carcaça de suínos machos castrados em terminação. Revista Brasileira de Zootecnia, v.36, n.4, p.1061-1068, 2007.

MIMBS, K.J.; PRINGLE, T.D.; AZAIN, M.J. et al. Effects of ractopamine on performance and composition of pigs phenotypically sorted into fat and lean groups. Journal of Animal Science, v.83, p.1361-1369, 2005.
PÉREZ, A.; OBISPO, N.E.; PALMA, J.P. et al. Efectos de La ractopamina y lisina sobre la deposición de grasa en cerdos seleccionados magros en la fase de engorde. Zootecnia Tropical, v.24, n.4, p.435-455, 2006.

STATISTICAL ANALYSES SYSTEM - SAS. SAS/STAT software version 8.02, Cary: 2002. 1686p.

SCHINCKEL, A.P.; LI, N.; RICHERT, B.T. et al. Development of a model to describe the compositional growth and dietary lysine requirements of pigs fed ractopamine. Journal of Animal Science, v.81, p.1106-1119. 2003.

SCHINCKEL, A.P.; RICHERT, B.T.; HERR, C.T. Variation in the response of multiple genetic populations of pigs to ractopamine. Journal of Animal Science, v.80, p.E85-E89, 2002 (suppl. 2).

SEE, M.T.; ARMSTRONG, T.A.; WELDON, W.C. Effect of a ractopamine feeding program on growth performance and carcass composition in finishing pigs. Journal of Animal Science, v.82, p.2474-2480, 2004.

SMITH, W.C.; PURCHAS, R.W.; Van ENKEVORT, A. et al. Effects of Ractopamina on the growth and carcass quality of entire male and female pigs fed ad libitum or at a restricted level. New Zealand Journal of Agricultural Research, v.38, p.373-380, 1995.

STITES, C.R.; McKEITH, F.K.; SINGH, S.D. et al. The effect of Ractopamina hydrochloride on the carcass cutting yields of finishing swine. Journal of Animal Science, v.69, p.3094-3101, 1991.

STOLLER, G.M.; ZERBY, H.N.; MOELLER, S.J. et al. The effect of feeding ractopamine (paylean) on muscle quality and sensory characteristics in three diverse genetic lines of swine. Journal of Animal Science, v.81, p.1508-1516, 2003.

TRAPP, S.A.; RICE, J.P.; KELLY, D.T. et al. Evaluation of four ractopamine use programs on pig growth and carcass characteristics. Purdue: Purdue University, 2002. p.62-71. (Swine Research Report).

WATKINS, L.E.; JONES, D.J.; MOWREY, D.H. et al. The effect of various levels of ractopamine hydrochloride on the performance and carcass characteristics of finishing swine. Journal of Animal Science, v.68, p.3588-3595, 1990.

WEBER, T.E.; RICHERT, B.T.; BELURY, M.A. et al. Evaluation of the effects of dietary fat, conjugated linoleic acid and ractopamine on growth performance, pork quality and fatty acid profiles in genetically lean gilts. Journal of Animal Science, v.84, p.720-732, 2006.

WEBSTER, M.J.; GOODBAND, R.D.; TOKACH, M.D. et al. Interactive effects between paylean (ractopamine $\mathrm{HCl}$ ) and dietary lysine on finishing pig growth performance, carcass characteristics and tissue accretion. Journal of Animal Science, v.80, p.78.(abstr.), 2002 (suppl. 2). 